This item was submitted to Loughborough's Research Repository by the author.

Items in Figshare are protected by copyright, with all rights reserved, unless otherwise indicated.

\title{
Types of place attachment and pro-environmental behaviors of urban residents in Beijing
}

\section{PLEASE CITE THE PUBLISHED VERSION}

https://doi.org/10.1016/j.cities.2018.07.012

\section{PUBLISHER}

(C) Elsevier

VERSION

AM (Accepted Manuscript)

\section{PUBLISHER STATEMENT}

This paper was accepted for publication in the journal Cities and the definitive published version is available at https://doi.org/10.1016/j.cities.2018.07.012

\section{LICENCE}

CC BY-NC-ND 4.0

\section{REPOSITORY RECORD}

Song, Zening, and Didier Soopramanien. 2018. "Types of Place Attachment and Pro-environmental Behaviors of Urban Residents in Beijing”. figshare. https://hdl.handle.net/2134/35693. 
Types of Place Attachment and Pro-Environmental Behaviors of Urban Residents in Beijing

\section{Zening Song}

International Business School, Beijing Foreign Studies University, No.19, Xisanhuan Beilu, Haidian, Beijing 100089, China

Email: songzening@bfsu.edu.cn

\section{Didier Soopramanien}

Lancaster University Management School, Lancaster University, UK International Business School, Beijing Foreign Studies University, No.19, Xisanhuan Beilu, Haidian, Beijing 100089, China

Email:didier@bfsu.edu.cn 


\begin{abstract}
Residents' engagement in pro-environmental behavior is crucial in tackling the environmental challenges that cities face. Research shows that residents who are attached to their place of residence are more likely to engage in pro-environmental behavior and, consequently, place attachment has been prescribed as a proenvironmental policy. However, previous research has not explored which specific aspect of place attachment is most effective at promoting different types of proenvironmental behavior. Furthermore, in the context of big cities which typically host both natives and migrants, different resident groups may be attached to their places of residence due to different reasons. This implies that different types of place attachment policies may be required for each group of residents. Using survey data in Beijing, China, we find that the social bonding dimension of place attachment is most effective at promoting pro-environmental behavior and that this relationship is stronger for native born residents and those with longer residency length. We also find that the effect of place social bonding is stronger for high-effort than low-effort proenvironmental behavior. Our findings have implications for the design and implementation of place attachment policies for local authorities in Beijing and in other big cities where different groups of residents cohabit. Generally, our research results imply that place attachment policies that focus on promoting social connections amongst urban residents to their place of residence will be most effective.
\end{abstract}

Key words: place attachment, pro-environmental behaviors, place social bonding 


\section{Highlights:}

The effect of the dimensions of place attachment varies across types of proenvironmental behaviours.

Place social bonding promotes high-effort pro-environmental behaviour the most.

Residency characteristics influence place social bonding which then influences higheffort pro-environmental behaviours. 


\section{Introduction}

Creating and designing sustainable cities is and remains a challenge in most countries especially those that are experiencing accelerating rates of urbanization. In China, the magnitude of this challenge is particularly daunting in big cities. With many rural areas being transformed into urban places and large numbers of rural workers migrating to urban areas (Chen et al., 2018), urbanization and the economic development have created environmental problems and challenges in the cities that are becoming bigger and bigger (Jiang et al., 2018). For example, more than $60 \%$ of the 669 large cities in China are experiencing water shortages, and the situation is severe in 110 of them (Liu, 2010). In 287 large cities where air quality is monitored, only $60.5 \%$ meet the standards of China's Ministry of Environmental Protection (Wang \& Chen, 2010). Some researchers, such as Jiang et al. (2018), found that in most Chinese cities residents' activities such as the usage of cars and heating contribute significantly to rising levels of pollution. Although city authorities in China are implementing policies to control residents' activities such as restricting the purchase and usage of cars, not all activities can directly be monitored or regulated. The environmental policy outcomes are dependent on residents' voluntary engagement in pro-environmental behaviours.

Engaging city residents in pro-environmental behaviors is difficult principally because the reward to taking part does not accrue directly to the individual. Gupta and Ogden (2009) contend that residents face a social dilemma when they are considering 
whether to engage in pro-environmental behaviors. In a social dilemma situation, the whole group benefits if all members take part in that activity (such as environmentally friendly activities), but the individual realizes that he/she is better off by not taking part since pro-environment participation typically requires additional effort or expenditure which acts as a disincentive. Furthermore, one cannot monitor or control whether other residents are going to take part and that embedded uncertainty itself can be demotivating.

To counteract the effect of social dilemma on pro-environmental behavior, Castaneda et al. (2015) propose that if we can make people feel part of the community by raising their sense of belonging to a place, we can potentially reduce the effect of social dilemma and may achieve more pro-environment cooperation amongst residents. In environmental psychology, that sense of belonging to a place is referred to as place attachment (Lewicka, 2011; Hernández et al. 2007; Hidalgo \& Hernandez, 2007). Generally, the literature has found that people who are attached to a place are likely to be more engaged in pro-environmental behaviors than those who feel less attached (Hernández et al, 2010; Ramkissoon, Weiler \& Smith, 2012; Scannell \& Gifford, 2010; Florek, 2011; Stedman, 2002).

Place attachment is a latent construct that has different sub-dimensions, and these sub-dimensions "are the reasons" people are attached to different sorts of places (Lewicka 2011, p.214). Williams and Vaske (2003) define place attachment as a construct of two sub-dimensions: place identity and place dependence. Place identity 
typically refers to the degree to which an individual describes how a particular place defines who he/she is and thus makes him/her different to other people who do not live in that place (Stedman, 2002). Place dependence refers to the functional element of attachment in terms of how a place meets the functional needs and goals of residents (Anton \& Lawrence, 2014). Another dimension, place social bonding, is proposed by Kyle, Graefe and Manning (2005). It refers to the feeling of belonging or membership to a group of people within a place, such as friends and family, as well as the emotional connection based on shared history, interests or concerns.

Although there is an established body of work on the positive relationship between place attachment and pro-environmental behavior, there has not been much attention devoted to studying which specific dimension of this construct matters the most in influencing pro-environmental behavior in the field of urban research. We assert that it is important to examine the reasons why people are attached to a place because this enables policy-makers to evaluate which specific dimensions of place attachment are most effective in engaging residents in pro-environmental behaviors.

In this paper, furthermore, we consider two levels of heterogeneity that can affect the relationship between the dimensions of place attachment and pro-environmental behaviors, which, as far as we are aware, have not previously been studied and are important in the context of cities and the management of environmental policies.

First, we examine the heterogeneity across types of pro-environmental behaviors since different types of pro-environmental behaviors are likely to be influenced by 
different sets of factors. Some environmentally friendly activities are easier to adopt and/or can benefit the individual directly. One can consider the case of residents paying attention to their domestic water consumption, which is a pro-environmental behavior, but the residents benefit directly by saving on their water bill. Thus, there is an inherent individual incentive and reward to engage in such types of pro-environmental activities. But other types of pro-environmental behaviors, such as buying organic food or using an electric car, may be more difficult or more expensive to adopt. Or, there is no direct reward to take part, and importantly, the individual is unsure whether other residents are going to reciprocate. This is where social dilemma, which we have already described above, is most likely to be experienced, and place attachment is likely to play a greater role in influencing engagement in high effort pro-environmental behavior (Ramkissoon, Smith \& Weiler, 2013).

Second, we consider how two different groups of residents relate to their city and how this might affect their engagement in pro-environmental behaviors. As is the case in many other countries, urbanization in China is driven by rural workers migrating towards cities (Chen et al., 2018). The context of this study is the city of Beijing and, like other cities in China, it has attracted many non-native residents. As we have discussed previously, the welfare outcome of pro-environmental behaviors will critically depend on engaging all types of residents; whether they are natives or migrants. Thus, we consider whether and how these two groups of residents relate to their city and how this relationship might affect their engagement in pro-environmental behavior. Previous research such as Hernández et al. (2007) finds that natives are more 
attached to the place of residence than migrants. However, there has not been much attention on whether the relationship between place attachment and pro-environmental behavior varies between natives and migrants. In the same vein, there has not been much work on whether that relationship varies across different types of proenvironmental activities between these two groups of residents. If the level of place attachment can explain engagement in different types of pro-environmental behaviors, it becomes important, from a policy perspective, to know whether the effects of the different dimensions of place attachment differ when we consider different types of residents. That is, if place attachment is to be used as policy instrument, it is important for city authorities to know whether the same type of place attachment policy can be used to engage both groups of residents.

The remainder of this paper is organized as follows. The second section presents the research hypotheses specifically highlighting the contributions of the research in relation to previous work in the area. The third section of the paper describes the data that is used and how the various constructs and variables are measured. The fourth section presents and discusses our empirical findings, and in the last section of the paper we discuss the conclusions and implications. 


\section{Research Hypotheses}

\subsection{Dimensions of place attachment and types of pro-environmental behaviour}

Most of research in the literature on the relationship between place attachment and its impact on residents' behaviors do not differentiate the roles of its dimensions. For example, Zenker and Rutter (2014) take place attachment as a unidimensional construct and find a positive relationship between place attachment and positive word of mouth about the place. Similarly, Belanche, Casalo and Orus (2016) apply city attachment as a one-dimensional variable to their research on how the attachment levels affect uses of urban services. Arifwidodo and Chandrasiri (2013) measure two aspects of sense of place but simplify them into one variable when testing their roles on environmental management practices. For the small number of studies which explore the effects of different dimensions of place attachment, the research findings are inconsistent. Scannell and Gifford (2010) study the impact of two sub-dimensions of place attachment, natural and civic place attachment respectively, on pro-environmental behaviors. Their research finds that natural place attachment (i.e. attachment to the physical features of a place) is more important in explaining pro-environmental behavior than civic attachment (i.e. the social connection with a place). These findings are different to Lo and $\operatorname{Jim}$ (2010) which demonstrate that social traits of place attachment are more important than physical ones on urban greenspace usage. In a different paper, these researchers find that only the affective aspect of place attachment plays a significant role (Lo and Jim, 2015). A possible explanation for the inconsistent 
results in the literature may be due to the nature of the dependent variables in these studies. In Lo and Jim (2015), for example, the focus of research is old city walls and trees which are unable to provide spaces for social interaction, while residential greenspace, the dependent variable in Lo and Jim (2010) can serve a significant social role for community residents.

Researchers have posited that the range of pro-environmental behaviours should be categorised since the different types of activities may have different sets of behavioural antecedents (Stern, 2000; Dono, Webb \& Richardson, 2010). In a visitor park context, Ramkissoon, Smith and Weiler (2013) empirically develop two constructs that differentiate between two types of pro-environmental behaviors: low and high effort behaviors respectively. Signing a petition, for instance, is low effort as opposed to volunteering which is high effort (Ramkissoon, Smith \& Weiler, 2013). In an urban context, similarly, some activities, such as using less water and re-using shopping bags, are easy to adopt and can even lead to cost savings, therefore directly benefiting the individual. Other types of behaviors, such as purchasing green products and advocating pro-environmental behaviors, require more effort and may not bring immediate individual benefits. The relationship between environmental behavior and social dilemma implies that it may be difficult to motivate individuals to participate in proenvironmental activities where the benefits are not tangible, immediate or monetary in nature and especially when they accrue to others rather than directly benefiting the individual (Martinsson, Myrseth \& Wollbrant, 2014). Thus, dimensions of place attachment that matter for pro-environmental behaviors may also be different 
depending on whether the pro-environmental behaviors demand more or less effort. Ramkissoon, Smith and Weiler (2013) represent a rare attempt at studying the effect of place attachment on different types of pro-environmental behaviors, and they find that place attachment positively influences both types of pro-environmental behavior but the effect is bigger in the case of high effort pro-environmental behaviors. However, unlike our research context which is a metropolitan city, their study context is a visitor park. Furthermore, they do not consider the direct impact of the different dimensions of place attachment on pro-environmental behaviors; instead, they include their effects indirectly through the main construct of place attachment.

Thus we propose the following hypothesis concerning the effect of the dimensions of place attachment on types of pro-environmental behaviors of urban residents.

H1: The dimensions of place attachment positively influence different types of proenvironmental behaviours.

\subsection{Types of residents, place attachment, and types of pro-environmental behaviour}

Previous research has shown that residency characteristics such as place of birth and length of residence significantly affect place attachment. For example, permanent residents and newcomers may differ in their reasons for their attachment to a place (Stedman, 2006). According to researchers such as Hui, Zhong and Yu (2012), nativeborn residents develop attachment to their birth place since they are born and have grown up in that place. Non-natives tend to develop attachment to a place when they 
actively engage themselves in local activities with the locals (Jackson, 2014; Deener, 2010). Length of residence has also been found to be a significant antecedent of place attachment. Anton and Lawrence (2014) and Hernandez et al (2007) find that the length of residence is positively associated with levels of attachment to a place. Casakin et al. (2015) find that the length of residence is positively associated with both place attachment and place identity.

We follow Casakin et al (2015) in our study and focus on two types of residency characteristics: place of birth and length of residence. That is, in order to be more confident about the comparison between migrant and native residents, we control for the length of residence in our research. Those migrants who have moved to a place for a long period of time may become attached to the city just like natives, and therefore we may not observe differences in their place attachment levels. We thus propose the following.

H2 Residency characteristics influence the dimensions of place attachment, such that being a migrant (as opposed to being born in the city) negatively influences the different dimensions of place attachment (H2a) and the length of residence positively influences the different dimensions of place attachment (H2b)

As we have discussed above, residents who have lived for different periods of time in the city may be attached to the city for different reasons, which can then influence their propensity to engage in different types of pro-environmental behaviors. Thus we 
propose the following hypotheses on the effects of residency characteristics on types of pro-environmental behaviors.

H3: Residency characteristics influence the types of pro-environmental behaviors such that being a migrant negatively influences engagement in different types of proenvironmental behaviors (H3a) and the length of residence positively influences engagement in different types of pro-environmental behaviors (H3b).

In addition to the direct effects of residency characteristics, we consider that these effects may be mediated by the dimensions of place attachment. For instance, a native may be more likely to engage in pro-environmental behavior compared to a migrant resident since he/she is more attached to the place. Or, similarly, a migrant is more likely to engage in pro-environmental behaviors only if he or she feels attached to the place. We go further in positing that this relationship may depend on the type of attachment and that the effect will vary for different types of pro-environmental behaviors. This relationship is summarized in hypothesis 4 .

H4: The effect of residency characteristics on the types of pro-environmental behaviors is mediated by different dimensions of place attachment, such that the negative effect of being a migrant on the types of pro-environmental behaviors is mediated by dimensions of place attachment (H4a) and that the positive effect of the length of residency on the types of pro-environmental behaviors is mediated by the dimensions of place attachment (H4b). 
The research framework is shown in figure 1.

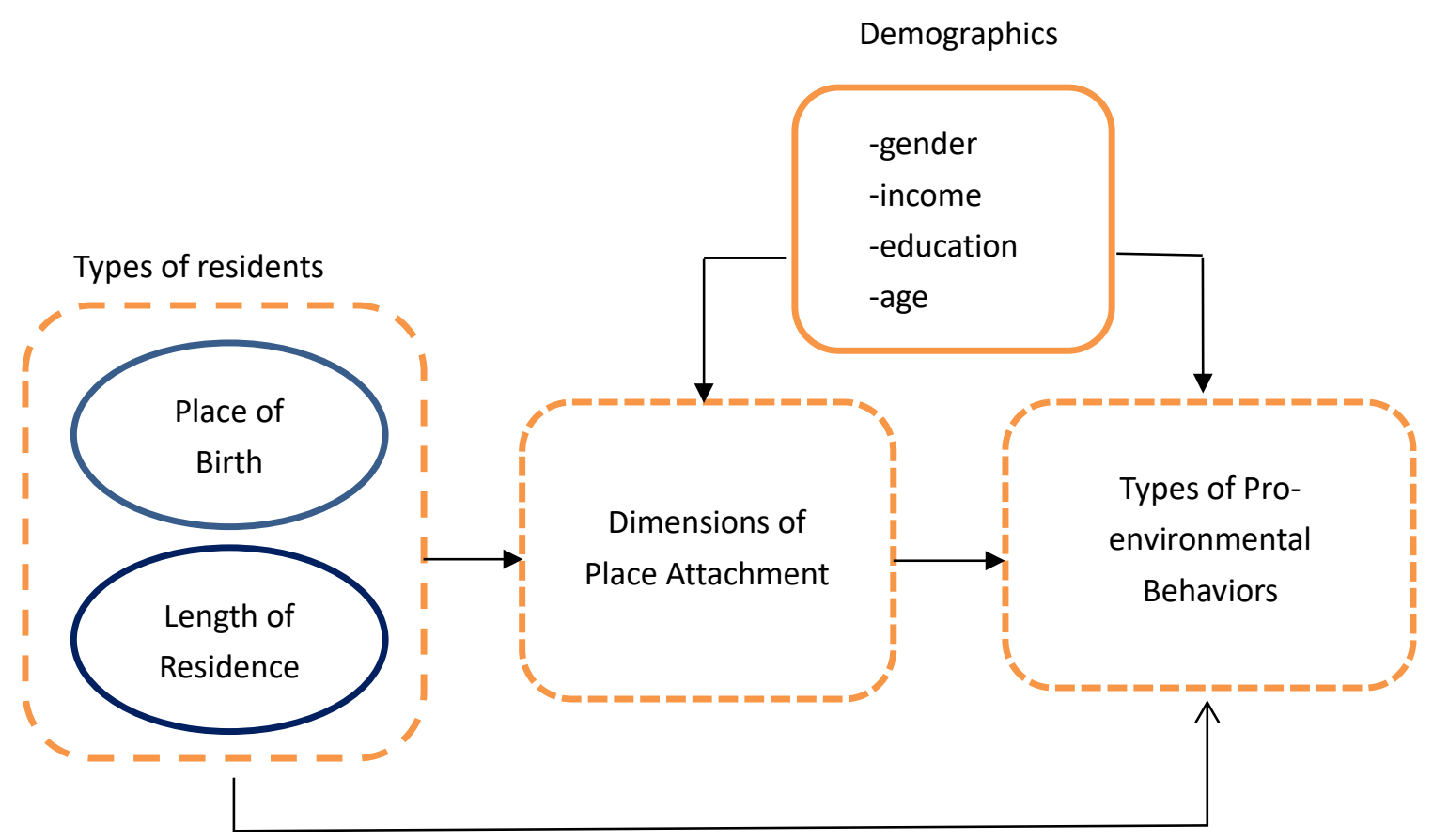

Figure 1 Research Framework

\section{Methodology}

\subsection{Sample and procedure}

The data for this research came from a survey conducted in Beijing, China. The survey was administered online using a professional online survey platform in China and we first analyzed the demographic profile of the respondents. To ensure the representativeness of the sample, especially to cater that in the online survey we did not have enough respondents in the age category of 50 and above, the same survey was then conducted offline by specifically asking interviewers to target those in that age category. For the offline data collection, nine research assistants were intensively trained and then sent to different parts of the city (e.g. city parks, malls, and municipal 
facilities). They approached older citizens at these locations randomly and asked them to complete the survey. A total of 310 urban residents of Beijing returned a complete survey, including 191 online responses and 119 offline.

The demographic characteristics of the sample are described in table 1. The respondents in the sample were residents of Beijing as of when the survey was conducted. Similar to Zenker and Rutter (2014), place of birth and length of residence were measured and controlled for place attachment. In our research, we defined residents who were born in Beijing as natives, and those not born in Beijing as migrants. $69 \%$ percent of respondents in our sample were migrants and $31 \%$ were native residents. $66 \%$ of the respondents reported more than ten years of residence in the city. 


\section{Table 1}

Frequencies for the demographic variables

\begin{tabular}{|c|c|c|c|}
\hline Variable & Category & $\mathrm{N}$ & Percentage \\
\hline \multicolumn{4}{|l|}{ Gender } \\
\hline & Male & 173 & 55.8 \\
\hline & Female & 137 & 44.2 \\
\hline \multicolumn{4}{|c|}{ Education } \\
\hline & Middle school or under & 34 & 11.0 \\
\hline & High school & 55 & 17.7 \\
\hline & Junior high & 26 & 8.4 \\
\hline & Undergraduate degree & 109 & 35.2 \\
\hline & Postgraduate and above & 86 & 27.7 \\
\hline \multicolumn{4}{|c|}{ Birth place } \\
\hline & Natives & 96 & 31.0 \\
\hline & Migrants & 214 & 69.0 \\
\hline \multicolumn{4}{|l|}{ Age } \\
\hline & under 24 & 28 & 9.0 \\
\hline & $25-34$ & 70 & 22.6 \\
\hline & $35-44$ & 77 & 24.8 \\
\hline & $45-59$ & 78 & 25.2 \\
\hline & 60 and above & 57 & 18.4 \\
\hline \multicolumn{4}{|c|}{ Income level Per month in RMB } \\
\hline & below 3000 & 78 & 25.2 \\
\hline & $3001-5000$ & 65 & 21.0 \\
\hline & $5001-8000$ & 63 & 20.3 \\
\hline & $8001-20000$ & 50 & 16.1 \\
\hline & 20001 and above & 54 & 17.4 \\
\hline \multicolumn{4}{|c|}{ Length of Residence } \\
\hline & Over ten years & 205 & 66.1 \\
\hline & $4-10$ years & 60 & 19.4 \\
\hline & 3 years or less & 45 & 14.5 \\
\hline
\end{tabular}

\subsection{Scale Measurement}

The research instrument was a structured questionnaire that used established measures with seven-point Likert type scales. The questionnaire included two latent constructs and ten single items. Latent constructs included multi-item scales adapted from previous research. All items were measured using 7-point Likert scales anchored from strong disagreement (1) to strong agreement (7). 
To ensure face and content validity in our empirical analysis of the constructs, we used established measurement scales from previous literature, asked five professors in the field of business and management to review the adapted instrument scale, and did a pilot testing with a small number of Beijing residents, which led to the modification and deletion of some of the questionnaire items. Some of the original items were not suitable in the context of Beijing and were modified or deleted according to the results of the expert review and the pilot study. For example, survey questions about the choice of transportation were revised since private cars in China cannot yet be considered as an effective alternative mode of transportation for most residents in Beijing.

The scales for the sub-dimensions of place attachment were based on the construct scales employed by Williams and Vaske (2003), Kyle, Graefe and Manning (2005), Scannell and Gifford (2010) and Ramkissoon, Smith and Weiler (2013). The scale tested three sub-dimensions of place attachment: place identity, place dependence, and place social bonding.

The survey questions for our research were adapted to fit the context of a city like Beijing as some of the original scales were designed for a specific purpose or context. Eight items were used to measure place attachment. The exploratory factor analysis revealed two constructs for place attachment. The first construct included all items of place identity and place dependence. It was referred to as personal place attachment (see table 2) in that it captured how individuals perceive their personal connection to the city. The second construct was related to social bonding aspect of place attachment 
similar to Brehm, Eisenhauer and Krannich (2004) and Ramkissoon, Smith and Weiler (2013). Place social bonding (see table 2) measured how individuals were connected to a place in an active and social manner, reflecting the participation of individuals in local activities and how they felt about what the place had to offer in that respect. These results of the factor analysis are similar to those reported by Lo and Jim (2015) where they also find two similar constructs in their factor analysis on the items measuring place attachment.

\section{Table 2}

Factor loadings for place attachment

\begin{tabular}{lcc}
\hline \multicolumn{1}{c}{ Items } & \multicolumn{2}{c}{ Factor loading } \\
\hline & $\begin{array}{c}\text { Factor 1 } \\
\text { Personal } \\
\text { attachment }\end{array}$ & $\begin{array}{c}\text { Factor 2 } \\
\text { Social bonding }\end{array}$ \\
\cline { 2 - 3 } & 0.564 & \\
Living in the city says a lot about who I am. & 0.674 & \\
The city means a lot to me. & 0.882 & 0.459 \\
The city is one of the best places for the type of work I do. & 0.720 & 0.715 \\
The city is one of the best places for what I like to do. & & 0.721 \\
My friends here strongly connect me to this city. & & 0.727 \\
I live in this city because my family is here. & & 2.125 \\
I like the local culture and tradition of this city. & & 26.565 \\
I often get involved in local projects and activities. & 2.211 & 27.641 \\
Eigenvalues & & \\
\% of variance explained & & \\
\hline
\end{tabular}

The scale for pro-environmental behaviors was developed based on the General Ecological Behavior scale (GEB) (Kaiser \& Wilson, 2000) and has been used in related studies such as in Scannell and Gifford (2010). Following the suggestions of experts review and the pilot study, some of the original items were modified or deleted since they were not suitable in the context of Beijing. The final list of 10 items covered all behavior domains in GEB (i.e. ecological garbage removal, water and power 
conservation, garbage inhibition, ecologically aware consumer behavior, volunteering in nature-protection activities, and ecological automobile use) and one of the items newly included in the GEB scale.

In the GEB scale (Kaiser \& Wilson, 2000), all the items were rated with logit values (the natural logarithm of the performance/non-performance ratio or the natural $\log$ odds), which represented respective behavioral difficulties. The bigger the logit value, the more effort consumers would have to put in in implementing the behavior. The exploratory factor analysis revealed two constructs for the 10 chosen items (see table 3). In the first category, the items were related to recycling and reuse (paper/bottle recycling and use of own shop bags) and/or concerned with daily living cost savings (water/electric usage). Their negative logit values indicated that they were comparatively easy for residents to engage in. Thus, the first factor was named low-effort behaviors. Items in the second category (such as "I buy organic food" and "I once pointed out to someone his or her un-ecological behavior") had bigger logit values, implying that their implementation required more specific knowledge, commitment of time, money, or social capital. These items were mainly related to ecological purchasing and public activism, and thus were categorized as high-effort behaviors. This categorization followed Ramkissoon, Smith and Weiler (2013)'s differentiation between low and high effort behaviors, and responded to the call in the literature to delineate different types of behaviors (Dono, Webb, \& Richardson, 2010). 


\section{Table 3}

Factor loadings for pro-environmental behaviors

\begin{tabular}{|c|c|c|c|}
\hline \multirow[b]{2}{*}{ Items } & \multicolumn{2}{|c|}{ Factor loadings } & \multirow[b]{2}{*}{$\begin{array}{l}\text { Difficulty } \\
\text { (logit } \\
\text { values) }\end{array}$} \\
\hline & $\begin{array}{c}\text { Factor } 1 \\
\text { Low effort } \\
\text { behaviors }\end{array}$ & $\begin{array}{c}\text { Factor } 2 \\
\text { High effort } \\
\text { behaviors } \\
\end{array}$ & \\
\hline I collect and recycle used paper. & 0.665 & & -0.25 \\
\hline $\begin{array}{l}\text { I usually throw empty bottles and cans into a } \\
\text { recycling bin. }\end{array}$ & 0.726 & & -0.32 \\
\hline I try to use less water when doing my laundry & 0.678 & & -0.66 \\
\hline $\begin{array}{l}\text { During hot days, I try to use air-conditioner } \\
\text { less often and make sure to set its } \\
\text { temperature no less than } 26 \text { degrees }\end{array}$ & 0.614 & & -0.22 \\
\hline $\begin{array}{l}\text { I bring my own shopping bags when } \\
\text { shopping. }\end{array}$ & 0.730 & & -0.23 \\
\hline $\begin{array}{l}\text { When I buy cleaning products (insecticide, } \\
\text { toilet cleaners, laundry detergent), I pay } \\
\text { attention to its environmental impact. }\end{array}$ & & 0.641 & 0.10 \\
\hline $\begin{array}{l}\text { I often talk with friends about problems } \\
\text { related to the environment. }\end{array}$ & & 0.742 & 0.00 \\
\hline $\begin{array}{l}\text { I once pointed out to someone his or her un- } \\
\text { ecological behavior. }\end{array}$ & & 0.616 & -0.16 \\
\hline I buy organic food. & & 0.737 & 0.19 \\
\hline $\begin{array}{l}\text { I tend to buy (or have already bought) } \\
\text { environmental friendly automobiles. }\end{array}$ & & 0.774 & -0.04 \\
\hline Eigen-values & 2.606 & 2.578 & \\
\hline$\%$ of variance explained & 26.057 & 25.784 & \\
\hline
\end{tabular}

Note: Logit values are from Kaiser \& Wilson (2000)

In the survey, we also have information on demographic characteristics such as age, gender, the education levels, and the income levels which we control for in the empirical analysis and, as is customary, we mainly discuss the impact of the focal variables in the discussion section. 


\section{Results and Discussion}

\subsection{Measurement validation}

PLS-SEM analysis was implemented using 'SmartPLS 3.0' (Ringle, Wende \& Becker, 2015) for the PLS-based path modeling.

The study first examined the indicator reliability, internal consistency reliability, convergent validity, and discriminant validity of the measurement model. According to Hulland (1999) and Hair et al. (2011), factor loading values of 0.70 or higher are preferred, and 0.4 or higher are acceptable for exploratory research. One item measuring place social bonding ("My friends here strongly connect me to this city") and one item measuring pro-environmental behavior ("During hot days, I try to use airconditioner less often and make sure to set its temperature no less than 26 degrees Celsius") had individual indicator reliability values lower than 0.6 and thus were not included. All of the remaining reliability indicators were close to the preferred level of 0.7. According to Bagozzi and Yi (1988), the average variance extracted (AVE) should be 0.5 or higher, composite reliability should be 0.7 or higher, and 0.6 or higher is acceptable for exploratory research. Table 4 shows the results, and all the constructs fulfilled these conditions. 


\section{Table 4}

Model specification - factor loadings and indictor reliability

\begin{tabular}{|c|c|c|c|}
\hline Constructs and scale items & Loadings & AVE & $\begin{array}{l}\text { Composite } \\
\text { Reliability }\end{array}$ \\
\hline Place Personal Attachment & & 0.562 & 0.836 \\
\hline PA 1 Living in the city says a lot about who I am. & 0.717 & & \\
\hline PA 2 The city means a lot to me. & 0.844 & & \\
\hline $\begin{array}{l}\text { PA } 3 \text { The city is one of the best places for the type of work I } \\
\text { do. }\end{array}$ & 0.742 & & \\
\hline PA 4The city is one of the best places for what I like to do. & 0.685 & & \\
\hline Place Social Bonding & & 0.574 & 0.802 \\
\hline Bond2 I live in this city because my family is here. & 0.778 & & \\
\hline Bond3 I like the local culture and tradition of this city. & 0.751 & & \\
\hline Bond4 I often get involved in local projects and activities. & 0.744 & & \\
\hline Low-effort Behaviors & & 0.543 & 0.826 \\
\hline ECO1 I collect and recycle used paper. & 0.699 & & \\
\hline $\begin{array}{l}\text { ECO2 I usually throw empty bottles and cans into a } \\
\text { recycling bin. }\end{array}$ & 0.738 & & \\
\hline ECO3 I try to use less water when doing my laundry & 0.706 & & \\
\hline ECO5 I bring my own shopping bags when shopping. & 0.799 & & \\
\hline High-effort Behaviors & & 0.528 & 0.848 \\
\hline $\begin{array}{l}\text { ECO6 When I buy cleaning products (insecticide, toilet } \\
\text { cleaners, laundry detergent), I pay attention to its } \\
\text { environmental impact. }\end{array}$ & 0.716 & & \\
\hline $\begin{array}{l}\text { ECO7 I often talk with friends about problems related to the } \\
\text { environment. }\end{array}$ & 0.792 & & \\
\hline $\begin{array}{l}\text { ECO8 I once pointed out to someone his or her un- } \\
\text { ecological behavior. }\end{array}$ & 0.675 & & \\
\hline ECO9 I buy organic food. & 0.719 & & \\
\hline $\begin{array}{l}\text { ECO10 I tend to buy (or have already bought) } \\
\text { environmental friendly automobiles. }\end{array}$ & 0.726 & & \\
\hline
\end{tabular}

For discriminant validity, the square root of AVE of each latent variable should be greater than the correlations among the latent variables (Fornell \& Larcker, 1981). Table 5 shows the results. All constructs that we used in the empirical analyses fulfilled this condition. 
Table 5

Fornell-Larcker criterion analysis for checking discriminant validity

\begin{tabular}{lcccc}
\hline & High & Low & PA & Bond \\
\hline High & $\mathbf{0 . 7 2 7}$ & & & \\
Low & 0.403 & $\mathbf{0 . 7 3 7}$ & & \\
PA & 0.100 & 0.149 & $\mathbf{0 . 7 4 9}$ & \\
Bond & 0.275 & 0.189 & 0.461 & $\mathbf{0 . 7 5 8}$ \\
\hline
\end{tabular}

Note:

High $=$ High-effort pro-environmental behaviors

Low $=$ Low-effort pro-environmental behaviors

$\mathrm{PA}=$ Place personal attachment

Bond $=$ Place social bonding

Off-diagonal entries are correlations; figures on the diagonal are the square root of AVE.

\subsection{Structural equation model results}

To estimate the proposed effects in our research model, a bootstrap re-sampling routine was conducted, and Figure 2 shows the results of the structural model assessment. Only the significant path coefficients are highlighted in the figure. 


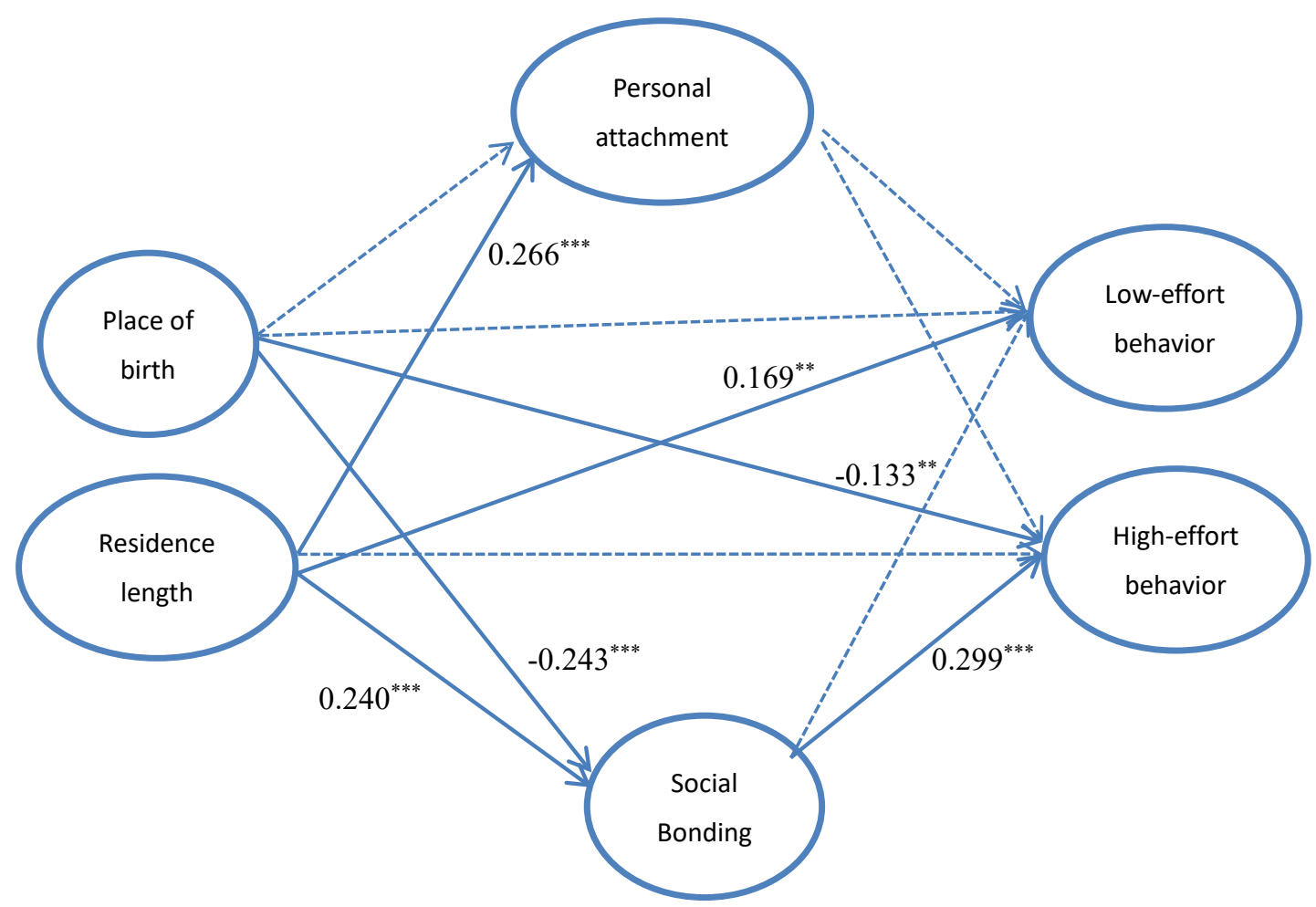

Note: Place of birth, native $=0$, migrant $=1$; Residence length, residence length of ten years or more $=1$, residence length of less than ten years $=0 ;{ }^{* * *} p<0.01 ;{ }^{* *} p<0.05$

\section{Figure 2 Structural model assessment}

Our results indicated that place social bonding had a significant impact on higheffort pro-environmental behavior (path coefficient $=0.299, p<0.01$ ), while the effect of place personal attachment was insignificant on both types of pro-environmental behavior. This would imply that place social bonding better captured residents' perception of their active and social involvement compared to personal place attachment. That is, residents who appreciated the activities that the city had to offer and importantly engaged in these activities would develop a certain form of affinity with the city, which then translated into engagement in activities such as environmentally friendly behavior that would benefit the place. In comparison, personal 
place attachment did not capture that sense of involvement and engagement and therefore had no impact on residents' engagement in pro-environmental behavior.

Thus, the results partially supported hypothesis 1 that place attachment was positively related to residents' engagement in pro-environmental behaviors, but only place social bonding had a significant impact and its effect was only on high effort proenvironmental behaviors. Our results are similar to Ramkissoon, Smith and Weiler (2013) who find that place attachment has a much bigger impact on high effort than on low effort pro-environmental behaviors. This finding is relevant for urban policy management when we ask the question: what should local authorities precisely do if place attachment matters in promoting pro-environmental behavior and different policies may be required to promote the different types of pro-environmental behaviors? Our findings suggested that residents were attached to a place and engaged in proenvironmental behavior not because they identified with the place but because they felt strong connections with fellow residents. The policy implication, in terms of which place attachment policy instrument to implement, in this case would be to emphasize residents' social connections with the place rather than identify with it.

Hypothesis 2 is concerned with the effect of residency characteristics on different dimensions of place attachment respectively. This is especially relevant in cities which are places of residence to both native-born residents and non-native migrants. More importantly, cities like Beijing host different types of residents who might be attached to the city for different reasons and this then can influence which 
dimensions of place attachment are more important in influencing the different types of pro-environmental behaviors for each group. Residents who have lived for different periods of time in the city may be attached to the city for different reasons which can then influence their propensity to engage in different types of pro-environmental behaviors.

Our findings showed that place of birth (being a migrant) significantly and negatively affected place social bonding ( path coefficient $=-0.243, p<0.01$ ). Similar to previous findings in the literature such as Hernandez et al (2007), native-born residents were found to be more attached to their place of residence than non-natives due to their experience with the place where they had grown up. Also, residence length positively and significantly affected both place personal attachment (path coefficient $=0.266$, $p<0.01$ ) and place social bonding (path coefficient $=0.240, p<0.01$ ). The results corroborated with previous research which has found that the length of residence is positively related to place attachment since longer residency helps develop local identity and social ties (Gustafson, 2009; Casakin et al 2015). Thus, generally, the results on the effect of residency characteristics on dimensions of place attachment supported hypothesis 2 .

Hypothesis 3 is concerned with the direct effect of residency characteristics on types of pro-environmental behaviors whilst hypothesis 4 posits that this effect may be mediated by the effect of the dimensions of place attachment. Our results showed that place of birth had a significant and negative impact on high-effort pro-environmental behavior ( ath coefficient $=-0.133, p<0.05$ ), and residence length had a significant and 
positive impact on low-effort pro-environmental behavior (path coefficient $=0.169$, $p<0.05)$. Thus, $\mathrm{H} 3$ was partially supported as different residency characteristics only affected some types of pro-environmental behaviors, such that being a migrant had a negative effect only on high effort behaviors and the length of residence was only significant in positively engaging residents in low effort behavior.

We then ran a bootstrapping analysis (Zhao et al., 2010) to test the mediation effect of place personal attachment and place social bonding respectively on the relationship between birth place/residence length and high/low effort behavior. As far as we are aware, both the direct effects of residency characteristics and the mediation effects of place attachment on the different types of pro-environmental behaviors have not been investigated previously. The results of the mediation analysis are shown in Table 6.

Table 6

Indirect effects

\begin{tabular}{lcccc}
\hline \multicolumn{1}{c}{ Path } & & \multicolumn{3}{c}{$\begin{array}{c}\text { Bias corrected bootstrap } \\
\text { 95\% confidence interval }\end{array}$} \\
\hline Place of Birth $\rightarrow$ PA $\rightarrow$ High & Indirect effect & SD & Lower & Upper \\
Place of Birth $\rightarrow$ SB $\rightarrow$ High & -0.020 & 0.018 & -0.055 & 0.016 \\
Place of Birth $\rightarrow$ PA $\rightarrow$ Low & -0.101 & 0.030 & -0.158 & -0.041 \\
Place of Birth $\rightarrow \mathrm{SB} \rightarrow$ Low & -0.028 & 0.019 & -0.067 & 0.011 \\
\hline Residence length $\rightarrow$ PA $\rightarrow$ High & -0.062 & 0.032 & -0.115 & 0.020 \\
Residence length $\rightarrow \mathrm{SB} \rightarrow$ High & 0.041 & 0.076 & -0.029 & 0.090 \\
Residence length $\rightarrow$ PA $\rightarrow$ Low & 0.121 & 0.033 & 0.064 & 0.193 \\
Residence length $\rightarrow \mathrm{SB} \rightarrow$ Low & 0.037 & 0.028 & -0.027 & 0.086 \\
\hline
\end{tabular}

Note: bootstrapping based on $\mathrm{n}=5000$ subsamples; Place of birth, native $=0$, migrant $=1$; Residence length, residence length of ten years or more $=1$, residence length of less than ten years $=0$; PA, place personal attachment; SB, place social bonding; High, high-effort behavior; Low, low-effort behavior.

The confidence interval for the indirect path of birth place (being a migrant $) \rightarrow$ social bond $\rightarrow$ high behavior excluded zero (95\% CI [-0.158, -0.041$])$. Since 
the direct effect of birth place (being a migrant) on high behavior was also significant and both effects pointed in the same direction (i.e. both effects were negative), the mediation was complementary mediation. As a type of partial mediation, complementary mediation means that both mediated and direct effects exist, and they point in the same directions (Zhao, Lynch \& Chen, 2010). Our results indicated that a migrant tended to engage less in high effort environmental behaviours partially because migrants were less socially connected with the city.

The confidence interval for the indirect path of residence length $\rightarrow$ social bond $\rightarrow$ high behavior excluded zero (95\% CI [0.064, 0.193]). Since the direct effect of residence length on high behavior was not significant, the mediation was indirect-only mediation (Zhao, Lynch \& Chen, 2010). This means that residents who had lived in the city longer tended to engage more in high-effort environmental behaviors simply because they felt more attached and connected socially. The stronger social bonding developed over years of residency enhanced residents' tendency to engage in proenvironmental behaviors.

No significant effects were found for the other indirect paths. Thus, only place social bonding was a partial mediator between residency characteristics (i.e. place of birth and residence length) and high effort pro-environmental behavior, and H4 was partially supported. The findings suggested that residents who were born locally and/or who had lived in the city for longer period tended to engage in high effort proenvironmental behaviours partially because they had become more socially connected with the city. 


\section{Conclusions and Implications}

\subsection{Place social bonding as a policy instrument for pro-environmental behavior}

The success or failure of cities' environmental policies ultimately rests on individuals' voluntary engagement in pro-environmental behaviors thus laying the foundation for place attachment policy intervention. Individual or micro monitoring of every city resident's environmental participation level is not feasible or practical and might even be perceived as invasive. Previous research such as Hernández et al. (2010), Scannell and Gifford (2010), Florek (2011), and Stedman (2002) has shown that residents' attachment levels to their city are indeed positively related to their engagement in pro-environmental behaviors. This would imply that city authorities can implement policies to raise the place attachment level of residents to motivate them to engage in pro-environmental behaviors.

We respond to the call by Scannell and Gifford (2010) that researchers must consider the multi-dimensional nature of place attachment and that there is a need to assess which of the variables that define the construct are more or less important in influencing residents' engagement in pro-environmental behavior. Furthermore, this provides a more specific avenue for place attachment policy intervention. That is, city authorities can identify which specific place attachment policy intervention will be more impactful. 
Our research indicates that place social bonding is a stronger predictor of proenvironmental behavior than personal place attachment. Our findings on the role of place social bonding corroborate with research on community studies, where place attachment is held as a product of social and behavioral processes rather than cognitive or perceptual (Stedman, 2002; Lewicka, 2011). In the same vein, Nye and Hargreaves (2010) argue that meanings of pro-environmental behaviors are constructed through the social interaction of people, which are then further translated into action. Georg (1999), in her study on three different eco-communities, notes that social interactions through participation in activities are significant in influencing pro-environmental behavior. Following on from that, our research on the role of place social bonding implies that in cities like Beijing, the social connection and bonding amongst residents play a substantive role, which connects people and thus enhances their engagement in proenvironmental behaviors. Social bonding may also entail a form of social pressure to do certain activities to fit in a community. Individuals may adopt certain behaviors because of their perceived expectations from others and also due to their expectations that others will behave in the same way.

5.2 Place attachment policies for pro-environmental behavior between two groups of residents and across two types of behaviors

Our research considers two levels of heterogeneity that might affect the relationship between place attachment and pro-environmental behavior: types of residents and types of behaviors. 
Beijing, like other cities in China, hosts two types of residents: those who were born in the city and those who have migrated there. The overall welfare outcome of pro-environment policies for all residents depends on the engagement of both types of residents. The novelty of the research and the value of the research insights are connected to the context of our research, big cities like Beijing, and this pertinently allows us to question whether place attachment policies remain as effective when we consider their impact on two types of residents of the city: natives and migrants. The research raises and questions the possibility of adopting similar policies in other cities in China that face similar problems of engaging residents in pro-environmental behaviors and, that, importantly, also host both migrants and natives who have to cohabit. In cities with different types of residents, city authorities must consider whether the same or different types of place attachment policies will be needed to target migrants and natives respectively.

We also consider the types of pro-environmental behaviors. Individuals may engage in low and high effort pro-environmental activities for different reasons. Previous research by Ramkissoon, Smith and Weiler (2013) finds that place attachment has a bigger effect on high effort than on low effort environment behavior in recreational destinations. In the context of cities, however, there has not been much research on the effect of place attachment on different types of behaviors. Our results show that the social connection between people and place is more important for high effort pro-environmental behaviors in the urban context. It indicates that low effort behaviors are easy to perform or they provide direct benefits to the individual, and thus 
the effect for place attachment policies will be limited for this type of behaviors. One the contrary, these policies will be more effective with respect to high effort behaviors. The more a resident feels attached to the city, the more he/she feels the need to behave more beyond her/his own individual benefit.

If place social bonding policies are effective for high effort behaviors, again, we question whether these policies will be effective for high effort behaviors for both natives and migrants of a city. Whilst previous researchers, such as Hernández et al. (2007), have studied whether migrants and native have different types and levels of attachment to a place, as far as we are aware, there has not been much research that investigates whether different types of place attachment play a mediating role between residency characteristics (i.e. place of birth and residence length) and the types of proenvironmental behaviors. Our results indicate that place social bonding partially mediates the link between birth place/residence length and high-effort behaviors. Thus, compared with native born residents and residents with longer residency, new migrants (i.e. those who have recently moved to the city) may yet to develop social connections with the city, which partially explains why they are less likely to engage in high-effort pro-environmental behaviors. Previous research, and ours too, has indicated that natives tend to have higher levels of place attachment compared to migrants. Our findings further demonstrate specifically that it is the sub-dimension of place social bonding that matters the most, especially for high-effort pro-environmental behaviors. 
In terms of urban environmental management, there is a clear policy implication that emerges from our results. Residents' sense of attachment to their city matters when it comes to engaging residents in pro-environmental choices and behaviors. A more specific policy implication in relation to our research findings concerns the role of place social bonding. This social aspect of place attachment provides a specific path through which cities can promote the pro-environmental behaviors of both natives and migrants. The findings of our research on the effect of place social bonding imply, for instance, framing pro-environmental behaviors as activities that form part of the city life and something residents can talk about can motivate people to take part. Thus, when designing public campaigns for encouraging pro-environmental behaviors, policymakers should advocate pro-environmental behaviors as part of social bonding/networking/community-life activities, especially when we consider different types of residents who have to cohabit in cities like Beijing. Furthermore, when residents feel more proactively connected (such as taking part in local activities) or socially connected to the city (with friends or other fellow residents), they are more likely to engage in pro-environmental behaviors because they enjoy living in the city in that manner rather than just living in the city for a functional purpose (such as solely for employment). Since migrants, especially those with short residency, tend to have a lower levels of social bond with the city and in turn are less likely to engage in proenvironmental behavior that demand more effort, it is therefore important for policy initiatives to target such residents and enhance their place social bonding. 


\subsection{Limitations}

This research has some limitations which provides interesting avenues for further research. Our empirical study context is Beijing and has this interesting feature of migrants and natives having to cohabit in the same city. There are many other cities in China and the world that share this same characteristic. Thus, our results are insightful to authorities in Beijing and other big cities in relation to how they should consider the use of place attachment policies to engage different types of residents in proenvironmental behaviors. We acknowledge that the sample that we use in the research is small but our research is exploratory in the sense that we are illustrating the benefits of some new propositions regarding the analysis of the relationship between specific dimensions of place attachment and types of environment behaviors and how that relationship differs between groups of residents. Related to this, we propose that further research should replicate some of our propositions in other cities particularly in those which do not have strict regulation policies on migration using larger samples and should also include other control variables. Chinese cities have implemented a household registration system called the Hukou system that is meant to regulate the flow of migrants from rural to urban areas in China. Under this policy migrants in these cities have to typically wait to become official residents of the city. Our research implies that only those who have lived in the city longer and thus are more likely to have the Hukou as official local-identity recognition will feel attached to the place and are willing to engage in pro-environmental behaviors. Thus, the findings may be specific to Chinese cities because of the strict migration regulations. 
Our results may reflect a particular feature in the context of a collective culture like China. According to Hofstede's cultural dimensions, interdependence and conformity to group norms are strongly emphasized in China and other collective cultures, and thus opinions of others have more impact on the individual in such societies in contract to individualist societies (Hofstede \& Minkov, 1991). Although Beijing is a typical city, future research should also consider the relationship between the types of place attachment and pro-environmental behavior in cities in other countries that are residential places to migrants from different cultural/national backgrounds. Further research can also include measures of cultural values to test the assumption of cultural reasons for the impact of place social bonding.

Moreover, our research on the role of place social bonding does indicate that researchers need to delve further into the importance of the influence of social connections between different groups of residents such as migrants and natives and whether this has an impact on their respective engagement in pro-environmental behaviors. 


\section{Acknowledgements}

This work was supported by Beijing Planning Office of Philosophy and Social Science ["A study on the pro-environmental behaviors of Beijing residents: an environmental psychology perspective", grant number: 14JGB056] and by the Fundamental Research Funds for the Central Universities ["Environmental citizenship behaviors: measurement and antecedents", grant number: 2018JJ009] 


\section{References}

Anton, C. E., \& Lawrence, C. (2014). Home is where the heart is: The effect of place of residence on place attachment and community participation. Journal of Environmental Psychology, 40, 451-461. doi: 10.1016/j.jenvp.2014.10.007.

Arifwidodo, S. D., \& Chandrasiri, O. (2013). The relationship between housing tenure, sense of place and environmental management practices: A case study of two private land rental communities in Bangkok, Thailand. Sustainable Cities \& Society, 8,16-23.

Belanche, D., Casaló, L. V., \& Orús, C. (2016). City attachment and use of urban services: Benefits for smart cities. Cities, 50, 75-81.

Brehm, J. M., Eisenhauer, B. W., \& Krannich, R. S. (2004). Dimensions of community attachment and their relationship to well-being in the amenity-rich rural west. Rural Sociology, 69(3), 405-429. doi: 10.1526/0036011041730545.

Brown, G., \& Raymond, C. (2007). The relationship between place attachment and landscape values: Toward mapping place attachment. Applied Geography, 27(2), 89-111. doi: 10.1016/j.apgeog.2006.11.002.

Bagozzi, R. P., Yi, Y., \& Nassen, K. D. (1998). Representation of measurement error in marketing variables: Review of approaches and extension to three-facet designs. Journal of Econometrics, 89(1), 393-421.

Castaneda, M. G., Martinez, C. P., Marte, R., \& Roxas, B. (2015). Explaining the environmentally-sustainable consumer behavior: a social capital perspective. Social Responsibility Journal, 11(4), 658-676.

Casakin, H., Hernández, B., \& Ruiz, C. (2015). Place attachment and place identity in Israeli cities: The influence of city size. Cities, 42, 224-230.

Casakin, H. P., \& Kreitler, S. (2008). Place attachment as a function of meaning assignment . Open Environmental Sciences Journal, 2(1), 80-87.

Chen, C., LeGates, R., Zhao, M., \& Fang, C. (2018). The changing rural-urban divide in China's megacities. Cities. (forthcoming)

Dolnicar, S., \& Grün, B. (2009). Environmentally friendly behavior can heterogeneity among individuals and contexts/ environments be harvested for improved sustainable management?. Environment \& Behavior, 41(5), 693-714. doi: $10.1177 / 0013916508319448$.

Dono, J., Webb, J., \& Richardson, B. (2010). The relationship between environmental 
activism, pro-environmental behavior and social identity. Journal of Environmental Psychology, 30(2), 178-186. doi:10.1016/j.jenvp.2009.11.006.

Deener, A. (2010). The 'black section'of the neighborhood: collective visibility and collective invisibility as sources of place identity. Ethnography, 11(1), 45-67.

Florek, M. (2011). No place like home: Perspectives on place attachment and impacts on city management. Journal of Town \& City Management, 1(4), 346-354.

Fornell, C., \& Larcker, D. F. (1981). Evaluating structural equation models with unobservable variables and measurement error. Journal of marketing research, 18(1), 39-50.

Gifford, R., \& Nilsson, A. (2014). Personal and social factors that influence proenvironmental concern and behavior: A review. International Journal of Psychology, 49(3), 141-157. doi: 10.1002/ijop.12034.

Gupta, S., \& Ogden, D. T. (2009). To buy or not to buy? A social dilemma perspective on green buying. Journal of Consumer Marketing, 26(6), 376-391. doi:http://dx.doi.org/10.1108/07363760910988201.

Georg, S.(1999). The social shaping of household consumption. Ecological Economics, 28(3), 455-466.

Hair, J. F., Ringle, C. M., \& Sarstedt, M. (2011). PLS-SEM: Indeed a silver bullet. Journal of Marketing theory and Practice, 19(2), 139-152.

Hair, J. F., Sarstedt, M., Ringle, C. M., \& Mena, J. A. (2012). An assessment of the use of partial least squares structural equation modeling in marketing research. Journal of the Academy of Marketing Science, 40(3), 414-433. doi:10.1007/s11747-011-0261-6.

Halpenny, E. A. (2010). Pro-environmental behaviors and park visitors: the effect of place attachment. Journal of Environmental Psychology, 30(4), 409-421. doi:10.1016/j.jenvp.2010.04.006.

Hernández, B., Hidalgo, M. C., Salazar-Laplace, M. E., \& Hess, S. (2007). Place attachment and place identity in natives and non-natives. Journal of Environmental Psychology, 27(4), 310-319. doi:10.1016/j.jenvp.2007.06.003.

Hofstede, G. J., \& Minkov, M. (1991). Cultures and Organizations: Software of the Mind. London: Mc-Graw Hill.

Hui, E. C. M., Zhong, J., \& Yu. K. (2012). Mobility and work-residence matching for new immigrants in Hong Kong. Habitat International, 36(4), 444-451. 
Hulland, J. (1999). Use of partial least squares (PLS) in strategic management research: A review of four recent studies. Strategic management journal, 20(2), 195-204.

Irwin, K. \& Brigan, N. (2013). Trust, Culture and Co-operation: A social dilemma Analysis of pro-environmental behaviors. The Sociological Quarterly, 54, 424449.

Jiang, P. Yang,J. Huang,C. and Liu, H. (2018). The contribution of socioeconomic factors to PM2.5 pollution in urban China, Environmental Pollution, Volume 233, pp 977-985.

Kaiser, F. G., \& Wilson, M. (2000). Assessing People's General Ecological Behavior: A Cross-Cultural Measure. Journal of Applied Social Psychology, 30(5), 952-978. doi: 10.1111/j.1559-1816.2000.tb02505.x.

Kyle, G., Graefe, A., \& Manning, R. (2005). Testing the dimensionality of place attachment in recreational settings. Environment and Behavior, 37, 153-177. doi: $10.1177 / 0013916504269654$.

Leonidou, C. N., \& Kvasova, O. (2010). Antecedents and outcomes of consumer environmentally friendly attitudes and behavior. Journal of Marketing Management, 26(13-14), 1319-1344. doi: 10.1080/0267257X.2010.523710.

Lewicka, M. (2011). Place attachment: How far have we come in the last 40 years?. Journal of Environmental Psychology, 31(3), 207-230. doi:10.1016/j.jenvp.2010.10.001.

Liu, J. (2010). China's road to sustainability. Science, 328(5974), 50. doi: $10.1126 /$ science. 1186234 .

Lo, A. Y. H., \& Jim, C. Y. (2010). Differential community effects on perception and use of urban greenspaces. Cities, 27(6), 430-442.

Lo, A. Y., \& Jim, C. Y. (2015). Protest response and willingness to pay for culturally significant urban trees: Implications for Contingent Valuation Method. Ecological Economics, 114, 58-66.

Jackson, L. (2014). The multiple voices of belonging: migrant identities and community practice in South Wales. Environment and Planning A 46(7), 1666-1681.

Martinsson, P., Myrseth, K. O. R., \& Wollbrant, C. (2014). Social dilemmas: When selfcontrol benefits cooperation. Journal of Economic Psychology, 45, 213-236.

Messick, D. M., \& Brewer, M. B. (1983). Solving Social Dilemma: A Review. Review of Personality and Social Psychology, 4, 11-44. 
Minton, E. A., Kahle, L. R., \& Kim, C. H. (2015). Religion and Motives for Sustainable Behaviors: a Cross-cultural Comparison and Contrast. Journal of Business Research, 68(9), 1937-1944. doi:10.1016/j.jbusres.2015.01.003.

Nye, M., \& Hargreaves, T. (2010). Exploring the social dynamics of pro-environmental behavior change. Journal of Industrial Ecology, 14(1), 137-149.

Payton, M. A., Fulton, D. C., \& Anderson, D. H. (2005). Influence of Place Attachment and Trust on Civic Action: A Study at Sherburne National Wildlife Refuge. Society and Natural Resrouces, 18(6), 511-528. doi:10.1080/08941920590947940.

Pickett-Baker, J., \& Ozaki, R. (2008). Pro-environmental products: Marketing influence on consumer purchase decision. Journal of Consumer Marketing, 25(5), 281-293. doi: http://dx.doi.org/10.1108/07363760810890516.

Ramkissoon, H., Smith, L. D. G., \& Weiler, B. (2013). Testing the dimensionality of place attachment and its relationships with place satisfaction and proenvironmental behaviors: A structural equation modelling approach. Tourism Management, 36, 552-566. doi:10.1016/j.tourman.2012.09.003.

Ramkissoon, H., Weiler B., \& Smith, L. D. G. (2012). Place attachment and proenvironmental behavior in national parks: The development of a conceptual framework. Journal of Sustainable Tourism, 20(2), 257-276. doi:10.1080/09669582.2011.602194.

Raymond, C. M., Brown, G., \& Weber, D. (2010). The measurement of place attachment: Personal, community, and environmental connections. Journal of Environmental Psychology, 30(4), 422-434. doi:10.1016/j.jenvp.2010.08.002.

Scannell, L., \& Gifford, R. (2010). The relations between natural and civic place attachment and pro-environmental behavior. Journal of Environmental Psychology, 30(3), 289-297. doi:10.1016/j.jenvp.2010.01.010.

Stedman, R. C. (2002). Toward a social psychology of place predicting behavior from place-based cognitions, attitude, and identity. Environment and behavior, 34(5), 561-581. doi: 10.1177/0013916502034005001.

Stedman, R. C. (2006). Understanding place attachment among second home owners. American Behavioral Scientist, 50(2), 187-205. doi: 10.1177/0002764206290633.

Steg, L., \& Vlek, C. (2009). Encouraging pro-environmental behavior: An integrative review and research agenda. Journal of Environmental Psychology, 29(3), 309317.

Stern, P. C. (2000). New environmental theories: toward a coherent theory of 
environmentally significant behavior. Journal of social issues, 56(3), 407-424.

Tumanan, M. A. R., \& Lansangan, J. R. G. (2012). More than just a cuppa coffee: a multidimensional approach towards analysing the factors that define place attachment. International Journal of Hospitality Management, 31(2) 529-534. doi:10.1016/j.ijhm.2011.07.012.

Wang, Z., \& Chen, J. M. (2010). A greener future for China's cities. Science, 327(5970), 1199. doi: 10.1126/science.327.5970.1199-a.

Williams, D. R., \& Vaske, J. J. (2003). The measurement of place attachment: Validity and generalizability of a psychometric approach. Forest Science, 49(6), 830-840.

Zenker, S., \& Rütter, N. (2014). Is satisfaction the key? The role of citizen satisfaction, place attachment and place brand attitude on positive citizenship behavior. Cities, 38, 11-17.

Zhao, X., Lynch Jr, J. G., \& Chen, Q. (2010). Reconsidering Baron and Kenny: Myths and truths about mediation analysis. Journal of consumer research, 37(2), 197206. 